\title{
INTRALESIONAL INOCULATION OF AUTOLOGOUS NON-CULTURED EPIDERMAL MELANOCYTE SUSPENSION IN VITILIGO- A NOVEL METHOD
}

\author{
Neeraj Srivastava1, Mayank Singh ${ }^{2}$, Sudhir Kumar ${ }^{3}$ \\ ${ }_{1}^{1}$ Associate Professor, Department of Skin and VD, MLB Medical College, Jhansi, U. P. \\ ${ }^{2}$ Associate Professor, Department of Pathology, MLB Medical College, Jhansi, U. P. \\ 3 Professor, Department of Surgery, MLB Medical College, Jhansi, U. P.
}

\begin{tabular}{l}
\hline BBSTRACT \\
Autologous noncultured epidermal melanocyte suspension (ANEM) inoculation is a valuable option in surgical treatment of \\
Vitiligo. However, this requires special set up and is a tedious procedure. In this study we tried to develop a simple method of \\
direct inoculation of ANEM without producing blisters on vitiligo patches.
\end{tabular}

\section{MATERIALS AND METHODS}

Totally 50 patients of stable vitiligo not responding to PUVA/PUVASOL therapy were streamlined for this study. Three identical vitiligo sites i.e. test sites, blister sites and control sites were selected. Direct intralesional inoculation of ANEM suspension was done at test sites while at blister sites it was inoculated after aspiration of blister fluid. At control sites, only PBS solution was given. Monthly follow up of the patients for pigmentation was done for three months. Statistical analysis was carried out by Chisquare test and $\mathrm{Z}$ test.

\section{RESULTS}

We found pigmentation at $50 \%$ of test sites and $70 \%$ of blister sites while no pigmentation seen at control sites. Results showed that chances of pigmentation were similar in face and neck region however it was slightly better at blister sites in trunk and limbs. Statistical analysis revealed that the responses between the test and blister sites are significant and also the response of the above method was more consistent on blister sites as compared to Test site.

\section{CONCLUSION}

This study found that the direct inoculation of melanocyte suspension is an effective and simple method for vitiligo patients unresponsive to PUVA therapy. This novel method of direct inoculation of ANEM suspension without producing blister can become a valuable alternative which can be done on outpatient basis.

\section{KEYWORDS}

Vitiligo, Melanocytes, ANEM, Pigmentation

HOW TO CITE THIS ARTICLE: Srivastava N, Singh M, Kumar S. Intralesional inoculation of autologous non-cultured epidermal melanocyte suspension in vitiligo- a novel method. J. Evolution Med. Dent. Sci. 2018;7(07):873-875, D0I: $10.14260 /$ jemds/2018/199

\section{BACKGROUND}

Vitiligo is a cosmetic problem often associated with psycho-social problems. The factors responsible for unsatisfactory outcome of medical therapeutic regimens include long duration, acrofacial and segmental vitiligo, poor compliance and the occurrence of adverse effects.

Vitiligo can be treated with a number of surgical interventions as punch graft, thin Thiersch's graft, melanocytes transplantation, tattooing and epidermal grafting. In autologous melanocytes transplantation both cultured $^{1}$ and non-cultured ${ }^{2}$ either in pure form ${ }^{1}$ or along with other epidermal cells ${ }^{3}$ is used. Transplantation of cultured autologous melanocytes is costly, time consuming with high chances of contamination. There are reports that the presence of keratinocytes is beneficial as they produce

'Financial or Other Competing Interest': None.

Submission 31-10-2017, Peer Review 01-02-2018,

Acceptance 07-02-2018, Published 12-02-2018.

Corresponding Author:

Dr. Mayank Singh,

Type IV/2, MLB Medical College Campus,

Jhansi-284128, U. P.

E-mail: singhmayank21@gmail.com

DOI: $10.14260 /$ jemds $/ 2018 / 199$

\section{(c) $(1) \ominus$}

growth factors and melanogenic peptides such as bFGF, mast cell growth factor and endothelin- 1.4

It has been possible to make economical transplantation of the autologous non-cultured epidermal suspension containing melanocytes (ANEM) by inoculating it in blisters. ${ }^{5}$ Delayed healing of transplanted sites and increased chances of infection in blister inoculative technique can be minimized by spreading the melanocytes over dermabraded skin but this is associated with a risk of drying up and dislodgement of ANEM. These disadvantages of dermabraded skin can be reduced by putting proper occlusive bandage at the transplanted sites. The present study (TANEM) for repigmenting depigmented skin lesions was based on the method described by Gauther and Surleve-Bazielle. ${ }^{2}$

The aim of present study was to experiment a novel method of transplantation of ANEM by direct inoculation without production of blister. Furthermore, an attempt was also made to compare the effect with that of inoculation of ANEM in blister.

\section{MATERIALS AND METHODS}

This study was experimental study. The participants were selected by convenient sampling. A total of 50 patients of Vitiligo attending the outpatient department of Skin and V.D, 
M.L.B. Medical College, Jhansi, over a period of six months, were included in the study. Inclusion criteria were patient with stable vitiligo not responding to PUVA/PUVASOL therapy given for at least one year. Exclusion criteria were, age below 8 years, women with pregnancy or lactation and any concurrent illness. Informed consent from the patients and routine investigations were done before performing the procedure. Since the study duration was short, we had to limit the sample size for convenience.

After preparation of the part (the medial side of thigh) injection of xylocaine with $2 \%$ adrenaline $(1 / 2,00,000)$ was given. The superficial punch grafts were, obtained with the help of disposable punches ( $3 \mathrm{~mm}$ or $4 \mathrm{~mm}$ ) and collected in solution containing, $0.25 \%$ trypsin, versene (EDTA), glucose in phosphate buffer saline (TVPG solution) and transported to the department of Microbiology where the tissue was incubated for $18-24 \mathrm{hrs}$ at $4^{\circ} \mathrm{C}$.

Three identical Vitiligo sites were selected test site (T), blister site B and control site (C). Equal number of ten sites on face, neck, trunk, upper limb and lower limb were selected for transplantation. At site (B) blister was produced by applying liquid nitrogen with cotton tipped applicator for 2030 second. The patients were advised to avoid rupture of blister which usually appeared after 8-10 hours of application.

After 18-24 hours in incubation, the graft was taken out of TVPG solution and put in Petri dish containing EDTA (1/5, 000 in saline) for $15 \mathrm{~min}$ at $370 \mathrm{C}$ in incubatory. The epidermis was separated from dermis with the help of tweezers and transferred in petri dish containing phosphate buffer solution ( $\mathrm{pH}$ 7.4-7.8) the basal layer of epidermis was rubbed gently with the help of blunt side of surgical blade and solution was vigorously pipetted out to obtain epidermal suspension. After that the cellular debris was removed and suspension was collected in sterile capped bottle.

The recipient site was prepared. At the test site (T) ANEM suspension was given direct intralesionally with the help of insulin syringe. The injection was carefully given at a depth of $1 \mathrm{~mm}$ approximately at the dermal epidermal junction $0.1 \mathrm{ml}$ of solution (ANEM) was inoculated to produce a wheal. Several such injections were given to cover the whole of the test side. At the selected control site (C) direct intralesional inoculation of PBS solution alone was given.

On the blister site (B) the blister fluid was partially aspirated with the help of insulin syringe and $0.5 \mathrm{ml}$ of solution (ANEM) was inoculated in the blister and the patients were asked to lie supine for 15 minutes so that the solution could settle down. The transplanted site B was then dressed with Sofratulle.

Monthly follow up of the patient was carried out up to 3 months. During the follow up, the patients were given PUVA SOL therapy thrice weekly using 8-methoxy psoralen at the dose of $0.6 \mathrm{mg} / \mathrm{kg}$ weight/treatment day. The observations obtained were tabulated and statistical analysis was done.

\section{Statistical Analysis}

To compare the results between test sites and blister sites $\mathrm{Z}$ test was applied using SPSS software. Chi square test was used for the distribution of positive pigmentation produced on various part of body according to sites.

\section{RESULTS}

Equal number of ten sites on face, neck, trunk, upper limb and lower limb were selected for transplantation of ANEM suspension with above mentioned procedures. Localized Vitiligo was the most common variety.

After one week, 30 tests sites (T) out of 50 (60\%) showed only erythema. While on the blister site (B) only erythema was observed in 14 (28\%), erythema plus crusting was observed in $20(40 \%)$ and erythema crusting, and discharge was observed in 7 (14\%) (Table-1).

After one month, 25 (50\%) test sites and 35 (70\%) blister sites showed pigmentation whiles no pigmentation was seen at control sites (Table-2). It was also revealed that the chances of positive responses at various sites of inoculation at both test and blister sites by this method was similar in case of face and neck region while response was better on blister site in case of trunk and limbs ( 60-80\%) as compared to test sites ( 40-50\%). After applying Chisquare test, $\chi^{2}$ value obtained was 1.905 and $p$ value was 0.7532 which was found to be insignificant. This shows that pigmentation produced after inoculation was distributed uniformly on various part of body and is associated with the procedures.

To compare the results between test sites and blister sites $\mathrm{Z}$ test was applied.

After applying $\mathrm{Z}$ test for comparison between Test site (T) and Blister site (B), $|\mathrm{Z}|=5.57773$ and $\mathrm{p}$ value was $<0.0001$ which is highly significant i.e. the difference in the responses between the test and blister sites are significant and the response of the above method was more consistent on blister sites as compared to Test site (T) (Table 3).

Pigmentation produced on Test site (25) was excellent at 3 sites (6\%), good at $7(14 \%)$, satisfactory at $8(16 \%)$ and poor at 7 sites $(14 \%)$. The response of transplantation varied according to type of Vitiligo with better response in localized type (Table- 4).

\begin{tabular}{|c|c|c|c|c|}
\hline Procedure & $\begin{array}{c}\text { Total } \\
\text { Sites }\end{array}$ & Erythema & $\begin{array}{c}\text { Erythema + } \\
\text { Crusting }\end{array}$ & $\begin{array}{c}\text { Erythema + } \\
\text { Crusting+ } \\
\text { Discharge }\end{array}$ \\
\hline $\begin{array}{c}\text { Test } \\
\text { (T site) }\end{array}$ & 50 & $30(60 \%)$ & 0 & 0 \\
\hline $\begin{array}{c}\text { Blister } \\
\text { (B site) }\end{array}$ & 50 & $14(28 \%)$ & $20(40 \%)$ & $7(14 \%)$ \\
\hline $\begin{array}{c}\text { Control } \\
\text { ( C site) }\end{array}$ & 50 & 0 & 0 & 0 \\
\hline $\begin{array}{c}\text { Table 1. Presence of erythema/crusting/discharge at 1 } \\
\text { week after inoculation }\end{array}$ \\
\hline
\end{tabular}

\begin{tabular}{|c|c|c|c|c|c|}
\hline \multirow{2}{*}{ 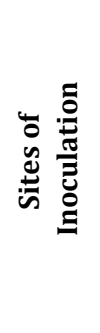 } & \multirow[t]{2}{*}{$\dot{z}$} & \multicolumn{2}{|c|}{ 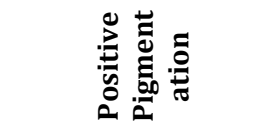 } & \multirow{2}{*}{ 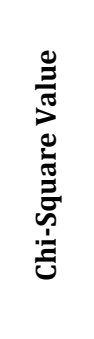 } & \multirow{2}{*}{ 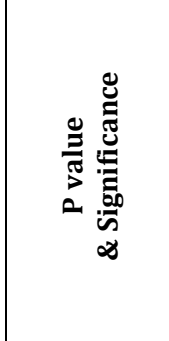 } \\
\hline & & 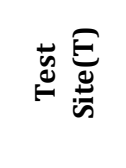 & 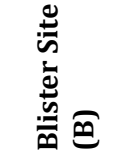 & & \\
\hline Face & 10 & $7(70 \%)$ & $6(60)$ & \multirow{4}{*}{$\begin{array}{l}1.905 \\
\mathrm{df}=4\end{array}$} & \multirow{4}{*}{0.7532} \\
\hline Neck & 10 & $6(60 \%)$ & $7(70 \%)$ & & \\
\hline Trunk & 10 & $5(50 \%)$ & $8(80 \%)$ & & \\
\hline $\begin{array}{c}\text { Upper } \\
\text { limb }\end{array}$ & 10 & $4(40 \%)$ & $6(60 \%)$ & & \\
\hline
\end{tabular}




\begin{tabular}{|c|c|c|c|c|}
\hline $\begin{array}{c}\text { Lower } \\
\text { Limb }\end{array}$ & 10 & $3(30 \%)$ & $8(80 \%)$ & \\
\cline { 1 - 3 } Total & $\mathbf{5 0}$ & $\mathbf{2 5}(\mathbf{5 0} \%)$ & $\mathbf{3 5}(\mathbf{7 0} \%)$ & \\
\hline Table 2. Distribution of positive pigmentation produced on \\
various part of body according to sites
\end{tabular}

\begin{tabular}{|c|c|c|c|c|}
\hline Tests & $\begin{array}{c}\text { Mean } \\
\pm \text { Standard } \\
\text { Deviation }\end{array}$ & \begin{tabular}{|c} 
Number of \\
Responses \\
on Site of \\
Inoculation
\end{tabular} & $|\mathbf{Z}|$ & $P$ value \\
\hline Test site (T) & $5 \pm 1.58113$ & 25 & \multirow[b]{2}{*}{5.57773} & \multirow{2}{*}{$\begin{array}{c}<0.0001, \\
\text { Highly } \\
\text { significant }\end{array}$} \\
\hline \begin{tabular}{|c} 
Blister Site \\
(B)
\end{tabular} & $7 \pm 1$ & 35 & & \\
\hline
\end{tabular}

Table 3. Comparison of test site (T) and blister site (B)

\begin{tabular}{|c|c|c|c|c|c|c|c|}
\hline 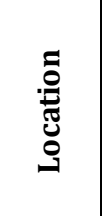 & 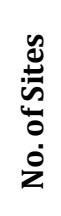 & 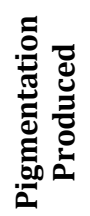 & 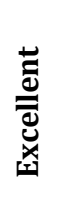 & $\begin{array}{l}\text { D̊ } \\
\text { D }\end{array}$ & 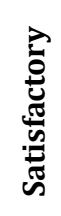 & $\dot{0}$ & 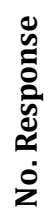 \\
\hline Face & 10 & 07 & 01 & 03 & 01 & 02 & 03 \\
\hline Neck & 10 & 06 & 01 & 02 & 02 & 01 & 04 \\
\hline Trunk & 10 & 05 & 00 & 02 & 01 & 02 & 05 \\
\hline $\begin{array}{c}\text { Upper } \\
\text { limb }\end{array}$ & 10 & 04 & 01 & 00 & 02 & 01 & 06 \\
\hline $\begin{array}{c}\text { Lower } \\
\text { limb }\end{array}$ & 10 & 03 & 00 & 00 & 02 & 01 & 07 \\
\hline Total & 50 & 25 & 03 & 07 & 08 & $\begin{array}{l}07 \\
\end{array}$ & 25 \\
\hline
\end{tabular}

\section{DISCUSSION}

Direct intralesional inoculation of ANEM was planned to overcome shortcomings of blister technique such as it can be performed only at limited sites, may cause hypo pigmentation/ hyper pigmentation and hypertrophic scar.

On applying the z-test to compare the pigment production at the test and blister sites, the p-value observed was less than 0.0001, implicating that the difference in the responses between the test and blister sites are significant and the response of the procedure was more consistent on blister sites than test site. Absence of pigmentation on all control sites showed that the result was not due to injection only.

The aim was to inoculate the ANEM solution at dermoepidermal junction, less response on the test sites could be due to inappropriate depth of the injection. There was significant lower response on the lower limb (30\%) by the intralesional inoculation (Test site) that could be due to difficulty in giving injection on the shin. In one patient with leucotrichia, the depigmented eyebrow was also repigmented supporting the hypothesis of retrograde migration of the melanocytes.
Outcome of transplant depended upon the type of Vitiligo and there was better response in cases of localized Vitiligo (73\%) in comparison to generalized Vitiligo (27.78\%). Thus, TANEM seems to be ideally suited for stable localized Vitiligo. Production of pigment by inoculation of ANEM does not seem to be influenced by the age, sex, site of the lesion, duration of disease and duration of PUVA therapy.

Follow up of most of the patients showed that the pigmentation produced was stable and the pigmentation was of similar colour as of adjoining normal skin. Repigmentation is likely to remain for a prolonged period, as was observed in this study.

\section{Limitations}

Since the calculated sample size was too high and thereby not feasible to include in this limited period of study, we had to limit the sample size for convenience.

\section{CONCLUSION}

Although, this new technique of direct transplantation of melanocytes suspension into the Vitiligo skin is an experimental study, it seems to be an effective and simple method for treating recalcitrant Vitiligo patients. Though the response of the new method was less on test sites as compared to blister sites but unlike the blister technique, the patients can be treated on an outpatient basis by direct intralesional inoculation method and so the compliance could be better. The use of this technique requires special laboratory equipment. However, in comparison with cultured cell, tissue graft this is an inexpensive and less timeconsuming procedure. However, further studies are required with more number of patients and with melanocytes count.

\section{REFERENCES}

[1] Olsson MJ, Juhlin L. Repigmentation of vitiligo by transplantation of cultured autologous melanocytes. Acta Derm Venereol 1993;73(1):49-51.

[2] Gauthier Y, Surieve-Bazeille JE. Autologous grafting with noncultured melanocytes: a simplified method for treatment of depigmented lesions. J Am Acad Dermatol 1992;26(2 Pt 1):191-4.

[3] Lontz W, Olsson MJ, Moellmann G, et al. Pigment cell transplantation for treatment of vitiligo: a progress report. J Am Acad Dermatol 1994;30(4):591-7.

[4] Halaban R, Langdon R, Birchall N, et al. Basic fibroblast growth factor from human keratinocytes is a natural mitogen for melanocytes. J Cell Bioi 1988;107(4):1611-9.

[5] Kumar S, Mishra RK, Kumar V, et al. Grafting of autologous non-cultured melanocytes for the treatment of Vitiligo: a pilot study. Indian J Dermatol 2003;48(4):206-8. 